\title{
Synthesis
}

\section{Evaluation of a Participatory Resource Monitoring System for Nontimber Forest Products: the Case of Amla (Phyllanthus spp.) Fruit Harvest by Soligas in South India}

\author{
$\underline{\text { R. Siddappa Setty }}^{1}, \underline{\text { Kamal Bawa }}^{1,2}$ Tamara Ticktin $^{3}$, and $\underline{\text { C. Made Gowda }}^{1}$
}

\begin{abstract}
Enhancing incomes from the sustainable harvest of nontimber forest products can help to maintain local livelihoods and provide local communities with economic incentives to conserve biodiversity. A key feature of a successful enterprise approach to the conservation of these products is a sound monitoring and evaluation program that involves all concerned stakeholders and leads to adaptive management. However, few studies have presented any of the approaches, successes, or challenges involved in participatory monitoring initiatives for nontimber forest products. We present our experiences using a participatory research model that we developed and used over a 10-yr (1995-2005) period for the wild harvesting of Phyllanthus spp. fruits (amla) by indigenous Soliga harvesters in the Biligiri Rangaswamy Temple Wildlife Sanctuary, South India. We describe the establishment and evolution of our participatory resource monitoring activities, compare some of the results of our activities to those obtained from monitoring using standard ecological approaches, and evaluate some of the successes and challenges associated with our participatory resource model. An initial step in this work was the establishment of Soliga-run enterprises for the processing and value addition of amla and other nontimber forest products. Participatory resource monitoring activities consisted of participatory mapping and assessments of fruit production, fruit harvest and regeneration combined with pre- and postharvesting meetings for sharing information, and adaptive management. Over the years, harvesters rejected, changed, and adapted various participatory resource monitoring methods to select those most appropriate for them. Visual estimates of fruit production made by harvesters at the forest level were very similar to estimates obtained using standard scientific monitoring protocols. Participatory research monitoring techniques that were effective included strategies for participatory resource mapping, fruit productivity estimation, and promotion of improved harvest techniques. Major challenges involved ensuring adequate incentives for monitoring activities that lead to benefits only over the longer term, such as monitoring of extraction and regeneration rates. Maintaining long-term participation and interest in the latter requires ensuring resource tenure.
\end{abstract}

Key Words: amla; fruit harvest; Soliga; participatory resource monitoring; nontimber forest products; Biligiri Rangaswamy Temple Wildlife Sanctuary

\section{INTRODUCTION}

Nontimber forest products (NTFP) play integral roles in the livelihoods and health of hundreds of millions of people across the globe (Iqbal 1993, Walter 2001, Vedeld et al. 2004). The dependence of local communities on NTFP led to the proposition that enhancing incomes from sustainable NTFP harvesting can help maintain local livelihoods as well as provide local communities with economic incentives to conserve biodiversity (e.g., Nepstad and Schwartzman 1992, Panayotou and Ashton
1992). This enterprise approach to conservation operates on the belief that greater economic returns can provide incentives for self-regulating harvest levels, and thus for conservation.

However, in many cases, the socioeconomic complexities involved in the use and management of wild resources can make sustainability an elusive goal (Kusters et al. 2006, Belcher and Schreckenberg 2007). Indeed, despite their potential, many commercially exploited NTFP continue to be overharvested (e.g., Vasquez and 
Gentry 1989, Murali et al. 1996, Peres et al. 2003, Ticktin 2004). A key feature of a successful enterprise approach to NTFP conservation is a sound monitoring and evaluation program that involves local harvesters and communities. Such participatory resource monitoring (PRM) makes it possible to evaluate the successes and shortcomings of the management effort and also enables managers to improve their management practices by adapting and modifying them. Among the many requirements of sustained involvement are sound ecological information, the provision of economic incentives related to participatory monitoring, capacity building that includes empowerment, and local policy and institutional reform. Nonetheless, to date very few studies have discussed participatory monitoring models for wild-harvested plant resources (see Cunningham 2001, Ticktin et al. 2002). If we are to develop effective models for working with local communities on sustainable resource use and conservation, we need to report on, test, and evaluate our efforts.

In this paper, we discuss our experiences using a participatory research model that we developed and used over a 10-yr period (1995-2005) for the wild harvesting of NTFP from the Biligiri Rangaswamy Temple Wildlife Sanctuary (BRT), South India. Although our work has encompassed a range of NTFP, here we report specifically on the PRM measures applied to two NTFP species harvested for their medicinal fruits: Phyllanthus emblica Linn and Phyllanthus indofischeri Bennet (Euphorbiaceae), both known locally as amla or nelli, or as "Indian gooseberry" in English. These two Phyllanthus species and other NTFP are harvested by indigenous Soliga communities living in the BRT and make up a significant portion of Soliga income (Hegde et al. 1996). The work reported here has been carried out by an NGO, the Ashoka Trust for Research in Ecology and the Environment, in collaboration with a Soliga-based partner NGO, the Vivekananda Girijana Kalyana Kendra, which has a long history of involvement in enhancing the health, education, and livelihoods of the Soligas. The participatory resource monitoring project was part of a larger project that sought to build the capacity of the Soligas to increase their income and sustainably manage NTFP. One part of this effort was the establishment of Soliga-run enterprises for the processing and value addition of amla and other NTFP (Bawa et al. 2007).

In this paper our objectives are to describe the establishment and evolution of our participatory resource monitoring activities, compare some of the results of our activities to those obtained from monitoring based on standard ecological approaches, and evaluate some of the successes and challenges associated with our PRM model.

\section{STUDY SITE}

The Biligiri Rangaswamy Temple Wildlife Sanctuary (BRT) is located between 11-13' N latitude and $77-78^{\prime} \mathrm{E}$ longitude in the southeast corner of Chamarajanagara district in the state of Karnataka, India (Fig. 1). The sanctuary is a confluence of the Western and Eastern Ghats. The western range has an undulating terrain, a network of valleys, slow west-flowing streams, and a number of hills with an average elevation of about $1350 \mathrm{~m}$. The sanctuary is divided into three administrative ranges: Yelandur, Chamarajanagara, and Kollegal. The eastern hills have an average elevation of about $1650 \mathrm{~m}$ and form a high ridge. The annual rainfall is $1362 \pm 159 \mathrm{~mm}$.

Ramesh (1989) broadly categorized the vegetation into five forest types: $61.1 \%$ dry deciduous forest, $28.2 \%$ scrub jungle, $6.5 \%$ evergreen forest, $3.8 \%$ savanna, and $0.8 \%$ shola. The BRT is rich in biodiversity, with 776 species of higher plants (Kamathy et al. 1967), more than 36 mammals excluding bats and rodents, 245 species of birds (Aravind et al. 2001), and 145 species of butterflies (N. A. Aravind and D. Rao, unpublished manuscript). The area has significant populations of elephant (Elephas maximus), tiger (Panthera tigris), gaur (Bos gaurus), sambar deer (Cervus unicolor), barking deer (Muntiacus muntjak), mouse deer (Tragulus meminna), and chittal or spotted deer (Axis axis).

The Soligas are an indigenous tribal community who live in the BRT. According to the last census, approximately 6000 Soligas live in forest villages called podus (tribal settlements). Traditionally, the Soligas were hunters and shifting cultivators and collected a wide range of nontimber forest products (NTFP). When the BRT area was designated a wildlife sanctuary in 1972, shifting cultivation and hunting were completely banned, and the Soligas were allocated small pieces of land to practice settled agriculture. The Soligas retained the sole right to NTFP extraction under the aegis of tribal cooperatives called Large-Scale Adivasi MultiPurpose Societies (LAMPS). LAMPS are set up by the Indian government for integrated tribal 
Fig. 1. Locator map of study site and tribal settlements.
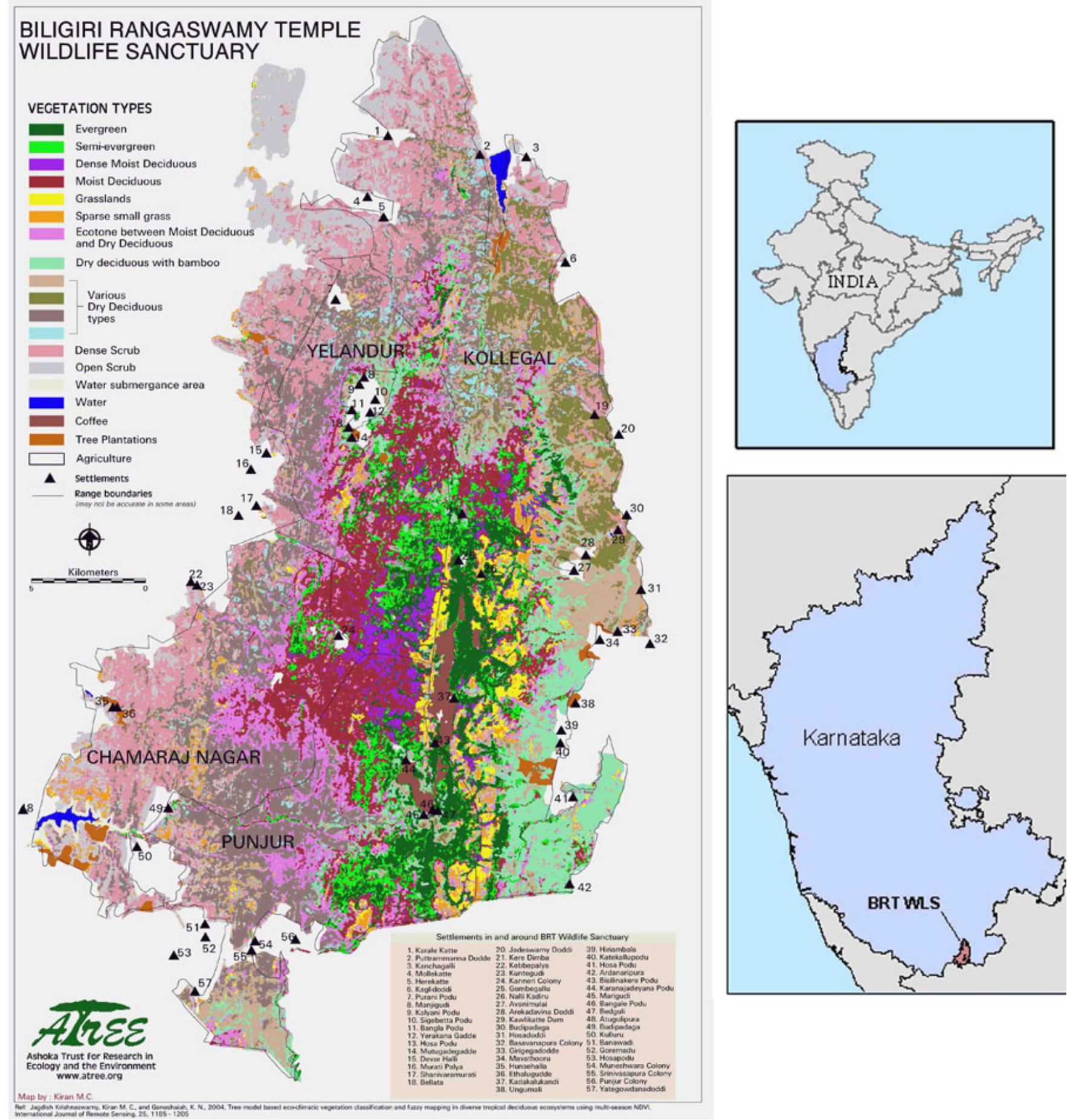
development through the marketing of NTFP in regions with significant tribal populations. Specifically, these LAMPS help tribal communities sell the forest produce they harvest and obtain local food items. There are three LAMPS associated with the BRT wildlife sanctuary.

Extraction of NTFP remains a major source of income for the Soligas. Hegde et al. (1996) estimated that the harvest of fruits from Phyllanthus emblica and $P$. indofischeri alone contribute approximately $6-11 \%$ of the total cash income in a Soliga household and that up to $50 \%$ of the cash income in a Soliga household may come from the extraction of NTFP. Aside from amla, Setty (2004) reports that the most important commercial NTFP for Soligas include honey from rock bees (Apis dorsata), lichens, soapnut (Acacia sinuata), and soapberry (Sapindus laurifolius).

\section{Amla (Phyllanthus emblica and P. indofischeri)}

P. emblica and P. indofischeri, known locally as amla, are distributed across parts of South and Southeast Asia. P. emblica is a medium-sized tree that grows $15-20 \mathrm{~m}$ tall and is found in dry deciduous forests. $P$. indofischeri trees are smaller (8-10 $\mathrm{m}$ tall) and are restricted to scrub forests. Older trees of both species tend to be parasitized by a hemiparasite (Taxillus tomentosus), and infestations have negative impacts on fruit production (Sinha and Bawa 2002).

Amla fruits mature in about mid-November. The fruits are round and vary from about 1.5 to $3.5 \mathrm{~cm}$ in size, with fruits of P. emblica tending to be smaller than those of $P$. indofischeri. Because amla fruits at a time of year when few other species are fruiting, it is thought to be an important food source for a number of ungulates such as the sambar deer (Cervix unicolor), spotted deer (Axis axis), barking deer (Muntiacus muntjak), four-horned antelope (Tetracerus quadricornis), and mouse deer (Tragulus meminna) and for primates such as the Hanuman langur (Semnopithecus entellus) and macaque (Macaca fascicularis). These frugivores may also help to disperse its seeds.

Amla fruits are very rich in vitamin C and are widely used by local people for a number of purposes, including pickles, jams, preserves, and jellies. In addition, amla fruits are an important ingredient of several Ayurvedic medicines. The fruits are also used for making dyes and shampoo, and the bark is used in the tanning industry and for making hair dye and ink (Uma Shaanker and Ganeshaiah 1997).

\section{ESTABLISHMENT AND EVOLUTION OF PARTICIPATORY RESOURCE MONITORING}

In 1995, in collaboration with the Vivekananda Girijana Kalyana Kendra (VGKK), we initiated activities to set up an enterprise to increase the Soligas' income from harvesting nontimber forest products (NTFP) in the Biligiri Rangaswamy Temple Wildlife Sanctuary (BRT). The core idea was to increase the Soligas' economic stake in the sanctuary's biotic resources by enabling them to generate additional income by processing NTFP on site and marketing the products directly, so as to capture a greater share of the final value. To manage the enterprise, a cooperative body called the Biligiri Soligara Kiru Aranya Uthpadana Samskarana Sanga ${ }^{\circledR}$ was established in 1997. Over the years, we initiated the following activities to strengthen the Soligas' capacity to monitor and protect NTFP.

\section{Preharvest meetings}

Preharvest meetings were initiated in 1996, and we held four or five meetings during the amla fruiting season in each settlement (podu) per year. The meetings lasted 45 minutes to an hour. The goals of the preharvest meetings were to discuss with local people the importance of resource monitoring; to identify traditional knowledge about fruit production, extraction, and regeneration; to collectively devise a format for recording observations and monitoring; and to discuss followup procedures. During these meetings we also discussed harvesting methods and emphasized the importance of certain conservation measures such as leaving a proportion of fruits on the tree for regeneration, removing hemiparasites, and not lopping off branches while harvesting fruits. Hemiparasites significantly increase amla mortality and reduce fruit production, and branch-cutting significantly decreases fruit production in the following years (Setty 2004).

In these preharvest meetings, the harvesters commented that there had been fluctuations in amla productivity over the years. They maintained that weeds or other alien invasive species and hemiparasite proliferation on the trees, in addition to low rainfall, were all reasons for low fruit 
productivity. They also noted that controlled, lowintensity ground fires do not affect fruit productivity, but that canopy fires do. They stated that regular, controlled low-intensity fires can reduce hemiparasite infestation.

\section{Participatory estimation of amla fruit production}

In 1998, Large-Scale Adivasi Multi-Purpose Societies (LAMPS) directors and amla harvesters from different BRT settlements began to visually estimate the amount of amla fruits produced in seven different areas of their demarcated land allotment of 11,000 ha. These seven areas were selected randomly by the harvesters. During the first year, the monitoring group consisted of about five LAMPS directors and 9-10 Soliga harvesters, and the exercise took one day. In each of the seven areas, the group walked along a 1-km stretch of the forest and visually estimated the amount of fruit available. At the end of the walk, the directors and harvesters discussed their estimates and reached a consensus estimate. The harvesters then drew a map on the ground using charcoal, and, using the estimated fruit yield for each of the seven areas, they calculated a comprehensive estimate for their entire forest range.

Starting in 1999, however, harvesters decided that it was not necessary to use the transects to estimate fruit production. Instead, they decided to make visual estimations of fruit production in each area while they were in the forest collecting firewood and other NTFP. To make the resource productivity map of each settlement, 10-15 harvesters gathered in one place to discuss their estimates and reached a consensus estimate for the each forest area. They then prepared the resource maps on the ground in charcoal. These maps were then documented on paper from 1998 through 2003. A single map was made in each settlement by 10-15 harvesters based on their fruit harvest area, and later a combined map for the entire forest range that integrated all the single maps was prepared with the help of social workers (Fig. 2).

These resource survey maps proved to be particularly useful because they made it possible to identify the areas in which fruit production was high. Moreover, they enabled the processing unit to estimate, ahead of time, the amount of fruit that would be available for purchase, processing, and marketing in any given year. This information in turn allowed them to find a good trader to whom to sell their fruits. The maps also allowed harvesters to identify areas that they should avoid harvesting if they felt that those areas had been repeatedly overharvested in the past. For instance, in 1999, before amla fruit collection started, harvesters from the Yelandur range showed an interest in avoiding collection in the area in which the 1998 maps indicated high levels of harvest.

\section{Participatory estimation of extraction rates}

Once the amla harvest season began, the rates and quantities of fruits extracted were estimated using three different methods. The first method involved estimates made at the level of individual trees. On a given harvesting day, four or five field assistants, all Soliga harvesters who had been trained by the staff of the Ashoka Trust for Research in Ecology and the Environment (ATREE), accompanied the amla harvesters to the forest and visually estimated the number of fruits they harvested per tree and the total number of fruits on the tree and recorded whether they removed hemiparasites or cut branches. They did this for 40-50 trees each day. To minimize the possibility that harvesters modified their behavior because they were being watched, only trained Soliga harvesters did the monitoring, and they were instructed not to make any comments to the harvesters. We also independently crosschecked the harvesting rates obtained by these trained harvesters with those we obtained by counting the number of fruits per tree in seven 1-ha plots, both before and after harvest. Both methods yielded very similar results.

At the end of the exercise, the information was then summarized by the social workers of the VGKK and the scientists of ATREE and shared with the harvesters during the postharvest meeting on the same day (see below). The rationale for this monitoring was to generate awareness about the current rates of fruit harvesting and branch cutting obtained from both harvester observations and counts from the 1-ha plots and to discuss the importance of improving harvest techniques by reducing levels of fruit extraction and branch cutting and increasing hemiparasite removal when harvesting fruit over the next few days. This exercise was carried out between 1995 and 1999. After 1999, the harvesters stated that they felt that the above method was useful for strengthening their knowledge, but that five years of it were enough. Therefore this method was discontinued. 
Fig. 2. Sample of the yearly fruit productivity map prepared by the community. Translated from the Soliga language, the title reads: Estimated quantities of amla fruits available in the forest of BiligiriRangana Betta, Yelandur taluka (range), during 1998-1999. In 1998-1999, amla harvesters from different settlements in theYelandur range of the Biligiri Rangaswamy Temple Wildlife Sanctuary visually estimated the amount of amla fruits produced within their demarcated land of 11,000 ha. The names of 32 forest areas were mentioned by the harvesters and recorded on the map, as is the total quantity of estimated amla fruit produced (25 t) and extracted (12.9 t) that year. In each of eight settlements, 10-15 Soliga harvesters were involved in the estimation of fruit production and extraction for their forest regions, which were then combined to create the total indicated on the map. Therefore, in total some 70 to 120 people were involved in preparing this map.

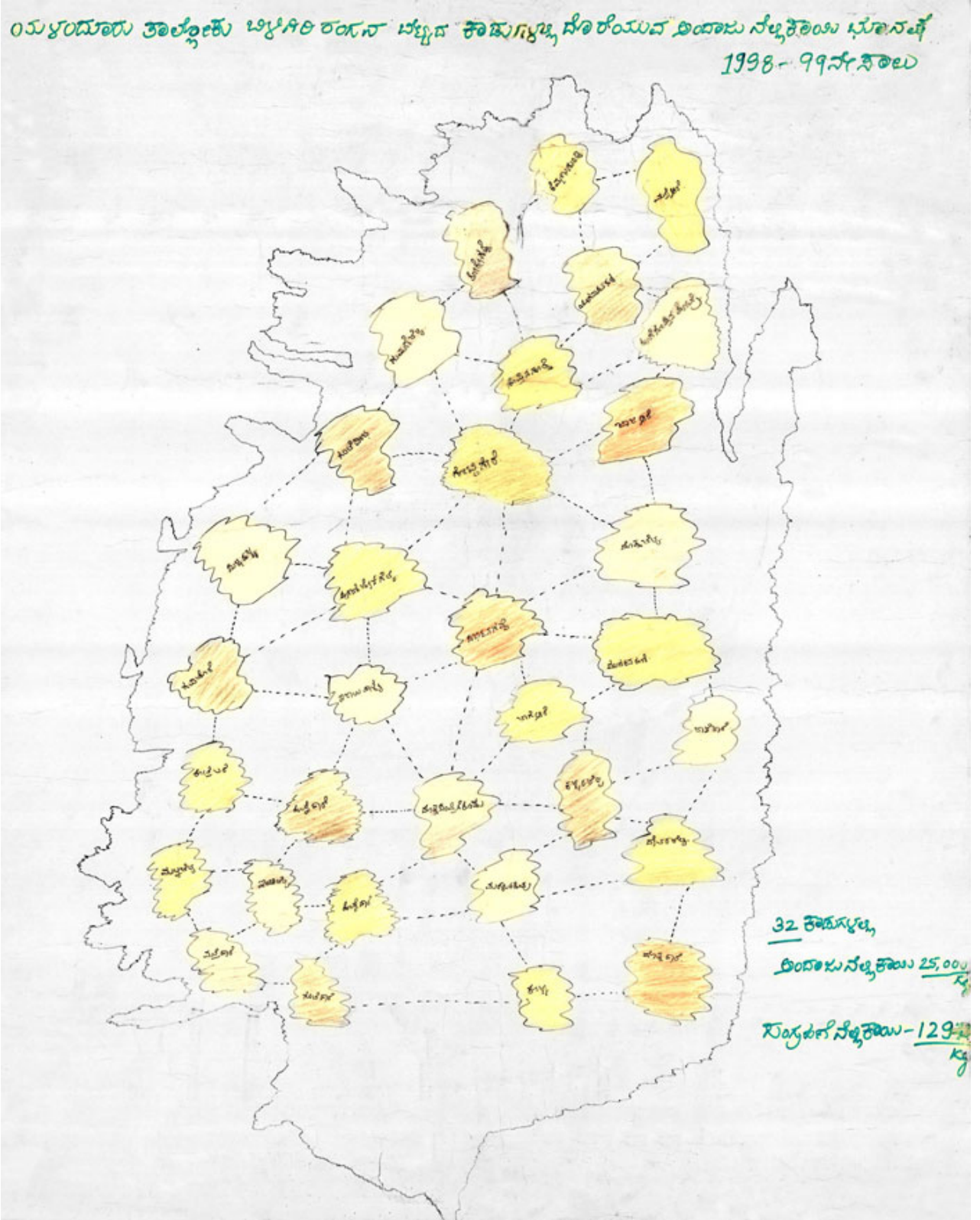


The second method involved a visual estimation of amla extraction rates at the forest level. The same harvesters who prepared the amla fruit productivity estimation maps for their respective sites and years also visually estimated the quantity of fruits extracted. Extraction levels were then marked on those same maps. ATREE coordinated this activity from 1996 to 2003 and then transferred it to LAMPS staff at the end of 2003.

The third method, carried out between 1997 and 2003, was based on the actual amount of fruit sold by the LAMPS each year (Table 1). That is, extraction was estimated each year from the LAMPS records of amla purchased from harvesters by the LAMPS for the areas in which fruit production was estimated. We used this method to cross-check the information obtained from the previous method.

The participatory monitoring of fruit harvest rates at the tree level (Method 1) revealed that rates of fruit extraction ranged from 76 to $98 \%$ of fruits per tree between 1995 and 1999. At the sanctuary level, however, extraction levels were much lower. Comparing visual estimates of fruit production from participatory resource monitoring (PRM) with LAMPS sales records illustrates that usually less than $60 \%$ of the fruit produced was harvested (Table 2 ). Other research has illustrated that, on average, 29 and $60 \%$ of the fruits were harvested at the population level for $P$. emblica and $P$. indofischeri, respectively (Setty 2004). These values are lower than might be expected because fruits from trees that do not bear heavy fruit crops are generally not harvested because of the high opportunity costs involved in harvesting. Specifically, P. emblica trees that bear fruit crops of less than $7.2 \mathrm{~kg}(\sim 1200$ fruits) are generally left unharvested, whereas $P$. indofischeri trees with crops of less than $2.6 \mathrm{~kg}$ ( 275 fruits) are not harvested (Setty 2004). Harvest intensity is higher in $P$. indofishceri because the trees have bigger fruits and are shorter, making them easier to climb (Setty 2004). In 2002-2003, amla harvest levels were particularly low (Table 1) because fruit productivity was exceptionally low, especially for $P$. indofischeri, whose trees produced only one to seven fruits each. It was therefore not worth the Soligas' time and effort to harvest amla that year. These kinds of trends have also been documented for other NTFP species elsewhere (Salafsky et al. 2003).

The one exception to the relatively low levels of amla harvest occurred in 2001-2002, when the
PRM results indicated that the actual amounts of fruit sold were much greater than the visual estimates in the study site (Table 1). The explanation is that, in that year, harvesters also collected fruits from forest ranges other than their own because no harvesting took place in the other forest ranges. This unusual situation was a result of the late negotiation of fruit sale by the LAMPS in the other regions. We do not have estimates of the quantity of fruit procured from the other ranges because the harvesters did not collect the fruits separately.

Overall, the visual method of estimating extraction at the individual tree level had the advantage of informing people through the postharvest meetings of the harvest levels carried out each day (see below). Estimates of extraction at the sanctuary level helped the community understand how much fruit they were extracting and how much was left in the forest for regeneration.

\section{Postharvest meetings}

During the harvest season, summaries of the results of the fruit extraction monitoring data were shared with the harvesters to improve the harvesting method for the next day. Harvesters attended meetings in their podus or in the forest before or after loading harvested fruits into the truck at the end of the day of harvest. The objectives of these meetings were to review the harvest in terms of both the amount of fruits harvested and the harvesting techniques used and to assess reactions to PRM.

Since 1996, with the participation of the Soliga community members who led the meetings, a total of 175 preharvest meetings and 126 postharvest meetings were carried out. The total attendance was 8626, including men, who are the amla harvesters, women, and children (Table 3). Although women, men, and children were encouraged to attend the meetings, most participants tended to be men $(80 \%)$. Women $(10 \%)$ were usually too shy to participate and were also occupied with household chores during the evenings. About $10 \%$ of the participants were children, who attended out of curiosity.

The number of pre- and postharvest meetings in the initial years was very high because we aimed to make the effort as participatory as possible. However, after the first three years of monitoring meetings, a survey conducted at the meeting held at the end of the harvest season revealed that, although $90 \%$ of the Soliga harvesters felt that the PRM 
Table 1. Estimates of fruit production and extraction for an 11,000-ha area in the Yelandur range of the Biligiri Rangaswamy Temple Wildlife Sanctuary. Values represent tons of amla (Phyllanthus emblica and $P$. indofishceri) fruit. The amount of available fruit was estimated by the visual estimation method as one of the participatory resource management activities. The amount of fruit harvested was estimated from records kept by the Large-Scale Adivasi Multi-Purpose Societies.

\begin{tabular}{lcc}
\hline \hline Year & Amount of available fruit & Amount of fruit harvested \\
\hline $1997-1998$ & NA & 254 \\
$1998-1999$ & 25 & 14 \\
$1999-2000$ & 145 & 83 \\
$2000-2001$ & 135 & 46.5 \\
$2001-2002$ & 208 & 336 \\
$2002-2003$ & 75 & 1.5 \\
$2003-2004$ & 113 & 65.5 \\
\hline
\end{tabular}

exercises were useful, $40 \%$ of them also said that they had learned enough from the previous exercises, that they understood the importance of the conservation measures, and that they wanted to be involved only in the estimation of resource availability. Based on these responses, the number meetings was then reduced (Table 3 ).

\section{Estimation of regeneration}

The PRM method of monitoring regeneration was initiated in 1997 and carried out once a year during December or January after the amla fruit harvest was completed. Every year, a team of 10-15 harvesters estimated the regeneration of amla in the forests by counting the seedlings, saplings, and adult stems of amla in three sites in the scrub forest and in three sites in the deciduous forest. At each site, the harvester team laid out three to four plots of 20 $\mathrm{m}^{2}$ and counted the number of amla seedlings, saplings, and adults in each. Initially, ATREE helped in this exercise, but later the harvesters did this on their own with the help of a social worker.

The sampling revealed that there was ample seed germination despite harvesting, with the number of seedlings and saplings per hectare more than five- fold the number of adult trees per unit area in all years (Fig. 3). These results are consistent with those obtained elsewhere in the BRT using standard scientific monitoring protocols in permanent plots (Ganesan and Setty 2004).

\section{Sharing results and capacity building}

In addition to the above-mentioned activities, awareness campaigns were organized by ATREE and VGKK in the form of dramas and folk art by the Soliga children and elders to highlight conservation and natural resource management issues. In addition, we carried out workshops to share the outcome of the PRM program with the Soliga community, prepared training manuals on PRM for use by the community and the enterprise unit, and carried out capacity building activities and LAMPS restructuring (Setty 2002). Finally, we also assessed the reactions of the community to PRM activities, which were evaluated at the end of each year through discussions in community meetings established for this purpose.

The harvesters and children felt that the folk dramas were both enjoyable and effective for learning about 
Table 2. Rates and patterns of amla (Phyllanthus emblica and P. indofishceri) fruit harvest in the Yelandur range of the Biligiri Rangaswamy Temple Wildlife Sanctuary, as recorded through participatory monitoring. Numbers in parentheses represent the number of trees sampled.

\begin{tabular}{lccc}
\hline \hline Year & Percent of fruits harvested/tree & $\begin{array}{c}\text { Percent of trees with hemiparasites } \\
\text { removed }\end{array}$ & Percent of trees with branches cut \\
\hline 1995 & $98 \pm 2(18)$ & NA & $24 \pm 34(18)$ \\
1996 & $76 \pm 15(278)$ & $75 \pm 34(278)$ & NA \\
1997 & $78 \pm 18(212)$ & $56 \pm 42(212)$ & NA \\
1998 & $83 \pm 13(66)$ & $77 \pm 32(66)$ & $9 \pm 15(42)$ \\
1999 & $89 \pm 10(47)$ & $63 \pm 38(47)$ & $18 \pm 31(47)$ \\
\hline
\end{tabular}

forest conservation. Harvesters maintained that the training manuals need to be kept in their settlements and shared with LAMPS and the forest department. During the first two years of assessment, $90 \%$ of harvesters said that both PRM and awareness meetings were helpful in conserving forest resources and improving livelihoods. In the third and fourth years of assessment, most harvesters said that estimation of fruit productivity and mapping were useful and that they would continue to do this, but that the awareness meetings were no longer necessary. They suggested that the latter could be held every five years. However, $75 \%$ of harvesters showed little enthusiasm for participating in the monitoring of regeneration. Fewer than $10 \%$ of harvesters felt that the whole process was timeconsuming and difficult.

\section{COMPARISON OF PARTICIPATORY RESOURCE MONITORING AND SCIENTIFIC ESTIMATES}

To assess the effectiveness of visual monitoring of fruit production levels as a component of participatory resource monitoring (PRM), we established an independent systematic estimate of fruit production. For this, 10 transects measuring $1000 \times 10 \mathrm{~m}$ were established randomly in the same seven forest areas in which the visual estimates were made by the harvesters. Several Soliga youth who had basic formal education participated in this exercise. The number of amla trees within each transect was recorded, and the number of fruits on each tree was counted. This monitoring took place before fruit dispersal and before any harvesting by the Soligas. These values were used to extrapolate the total amount of fruit available for the entire area of 11,000 ha. One hundred fruits from each forest were also selected randomly and weighed to obtain the average weight of the fruit and to estimate the harvest in tons for the entire forest range.

The visual estimates of amla fruit production made by the harvesters were very similar to those obtained using the scientific transect methods (Fig. 4). Although visual estimates can be biased and vary from person to person, these results suggest that in this case the visual methods were a good measure of actual fruit production. The high accuracy in this case was probably due to the fact that the estimates represented a consensus among 10 to 15 experienced harvesters in each podu (village); in addition, the people making the estimates were largely the same ones from year to year, and the estimates were on a large scale. Therefore, this aspect of monitoring by the community is very effective, as well as more rapid and cheaper than information obtained from standard scientific methods.

Fruit production for both species combined ranged from 35 to more than $200 \mathrm{t} / \mathrm{yr}$ for the 11,000-ha area, and fruit production levels in 2001 were more than 
Table 3. Number of annual pre- and postharvest meetings that took place in the Yelandur range of the Biligiri Rangaswamy Temple Wildlife Sanctuary between 1996 and 2004. Participatory monitoring data were shared at the postharvest meetings.

\begin{tabular}{lcccc}
\hline \hline Year & \multicolumn{2}{c}{ Preharvest meetings } & \multicolumn{2}{c}{ Postharvest meetings } \\
& No. of meetings & No. of participants & No. of meetings & No. of participants \\
\hline $1996-1997$ & 17 & NA & 30 & 1501 \\
$1997-1998$ & 79 & 2560 & 13 & 438 \\
$1998-1999$ & 22 & 580 & 22 & 484 \\
$1999-2000$ & 15 & 205 & 10 & 204 \\
$2000-2001$ & 15 & 190 & 10 & 225 \\
$2001-2002$ & 9 & 157 & 15 & 525 \\
$2002-2003$ & 9 & 160 & 10 & 420 \\
$2003-2004$ & 9 & 152 & 16 & 825 \\
\hline
\end{tabular}

three times greater than in 1998. Both sets of data illustrated the great variation in fruit production over time and therefore the importance of annual monitoring to predict in advance the amount of fruit available for any given year.

\section{EVALUATION OF THE PARTICIPATORY MODEL}

\section{Comparing harvest practices in areas with high vs. low participatory resource monitoring}

In the past, the Soliga self-regulation of the harvesting of nontimber forest products (NTFP) likely occurred within the context of their traditional tenure system, in which families had tenure over different parts of the forest. However, that tenure system has largely disappeared since the creation of the Biligiri Rangaswamy Temple Wildlife Sanctuary (BRT). Moreover, NTFP harvest levels were generally much lower in the past than they are today, because the Soliga only become economically dependent on NTFP sale when the BRT was established and their traditional practices of shifting agriculture and hunting were banned.
Therefore, in recent years traditional Soliga monitoring systems and self-regulation of harvest levels have largely given way to harvesting regulated by market demand for products.

To assess some of the impacts of PRM on harvesting methods, in 1998 we documented and compared harvesting techniques in an area of high PRM effort (the Yelandur range), vs. an area in which our efforts were much less intensive (the Chamarajanagara range). In Yelandur, many harvest monitoring meetings took place (a total of 75), and the proportion of people who participated was high (95\%). In contrast, in Chamarajanagara, only 25 meetings were held, and the proportion of people who attended them was lower (40\%).

In both areas, we accompanied harvesters to record the level of amla extraction from 40 individual trees, including the number of fruits left on the tree, the percentage of branch cutting, and the quantities of hemiparasites removed by the harvesters. Although we have no information on branch cutting rates before PRM was started, the significantly lower levels of branch cutting in Yelandur vs. Chamarajanagara $\left(\chi^{2}=34.95 ; p<0.0001\right)$ suggests 
Fig. 3. Population structure of amla (Phyllanthus emblica and P. indofishceri) estimated using participatory resource management methods.

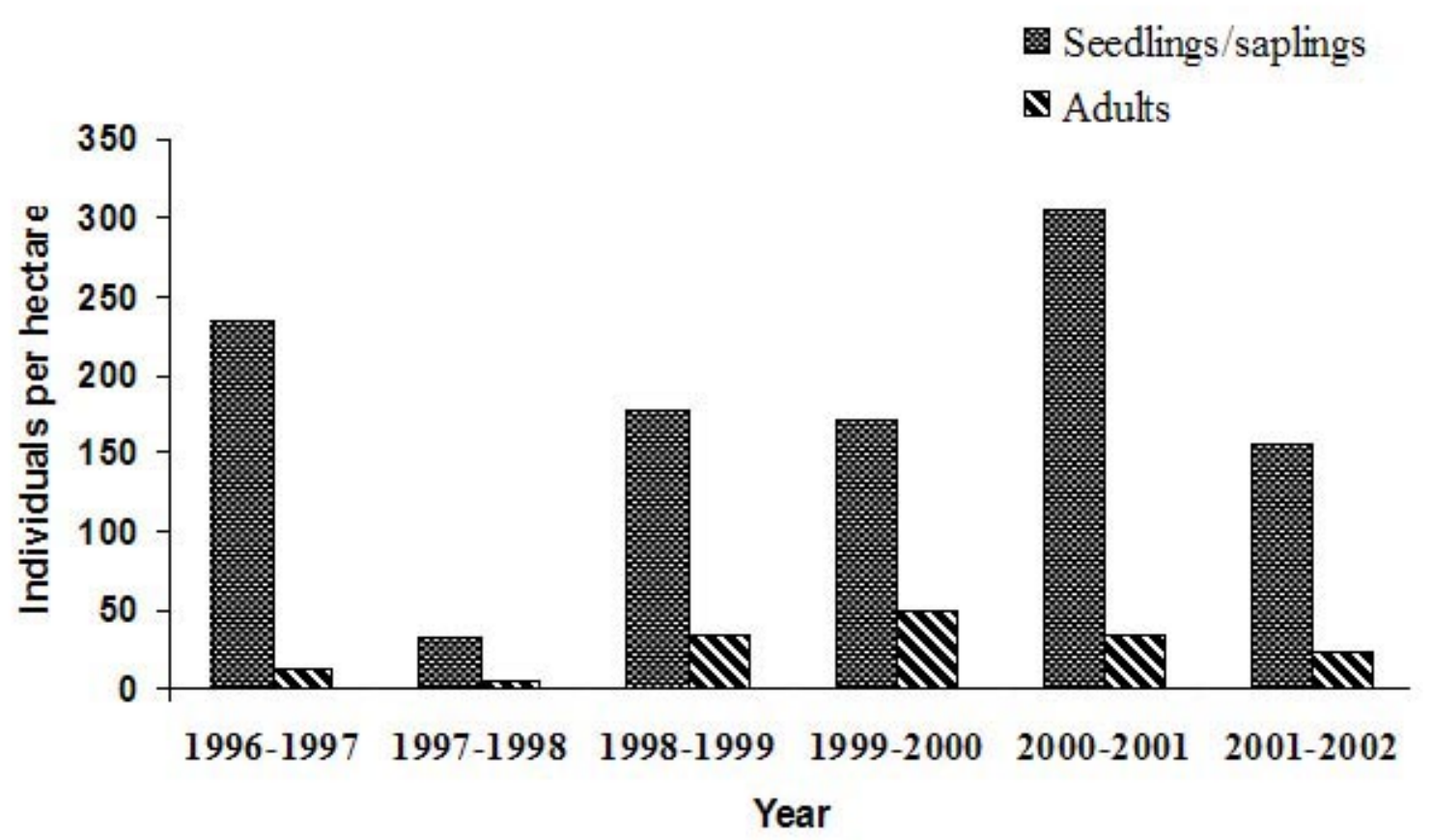

that PRM has resulted in lower rates of this practice (Fig. 5). Because branch cutting leads to significant decreases in fruit productivity (Setty 2004), this decline can be expected to lead to greater productivity. The proportion of fruits harvested was also lower in Yelandur than in Chamarajanagara, although the reverse was true for the proportion of trees with hemiparasites removed (Fig. 5). However, these differences were not significant $\left(\chi^{2}\right.$ $=2.24, p=0.4 ; \chi^{2}=2.24, p=0.13$, respectively).

Our data also illustrate a strong negative correlation between the percentage of trees that had branches lopped off and the number of postharvest meetings $\left(r^{2}=0.93\right)$. Similarly, it illustrates a strong negative correlation between the number of fruits harvested and the number of harvesters participating in postharvest meetings $\left(r^{2}=0.84\right)$. This suggests that the sharing of results on harvest levels and practices with harvesters during the postharvest meetings was likely successful in generating more awareness about prudent harvesting methods. However, there was no strong correlation between the number of meetings held per year and the percentage of fruits harvested $\left(r^{2}=0.37\right)$. Therefore, the number of meetings held did not make any difference in terms of harvesting techniques; the crucial factor appeared to be the number of people attending. In addition, it was specifically the number of people attending postharvest meetings, at which the monitoring information on harvesting rates and methods for each day were shared, that positively influenced harvesting practices. This illustrates the importance of participatory research: Harvesters only changed their harvesting methods when they were part of the process of evaluating them. Our results are also supported by other studies that suggest that the higher conservation awareness of harvesters in the BRT as compared to other areas may because of the participatory work of NGOs and community-based organizations (Uma Shaankar et al. 2004). 
Fig. 4. Estimation of annual fruit production of amla (Phyllanthus emblica and P. indofishceri) based on visual estimations by harvesters vs. transect counts.

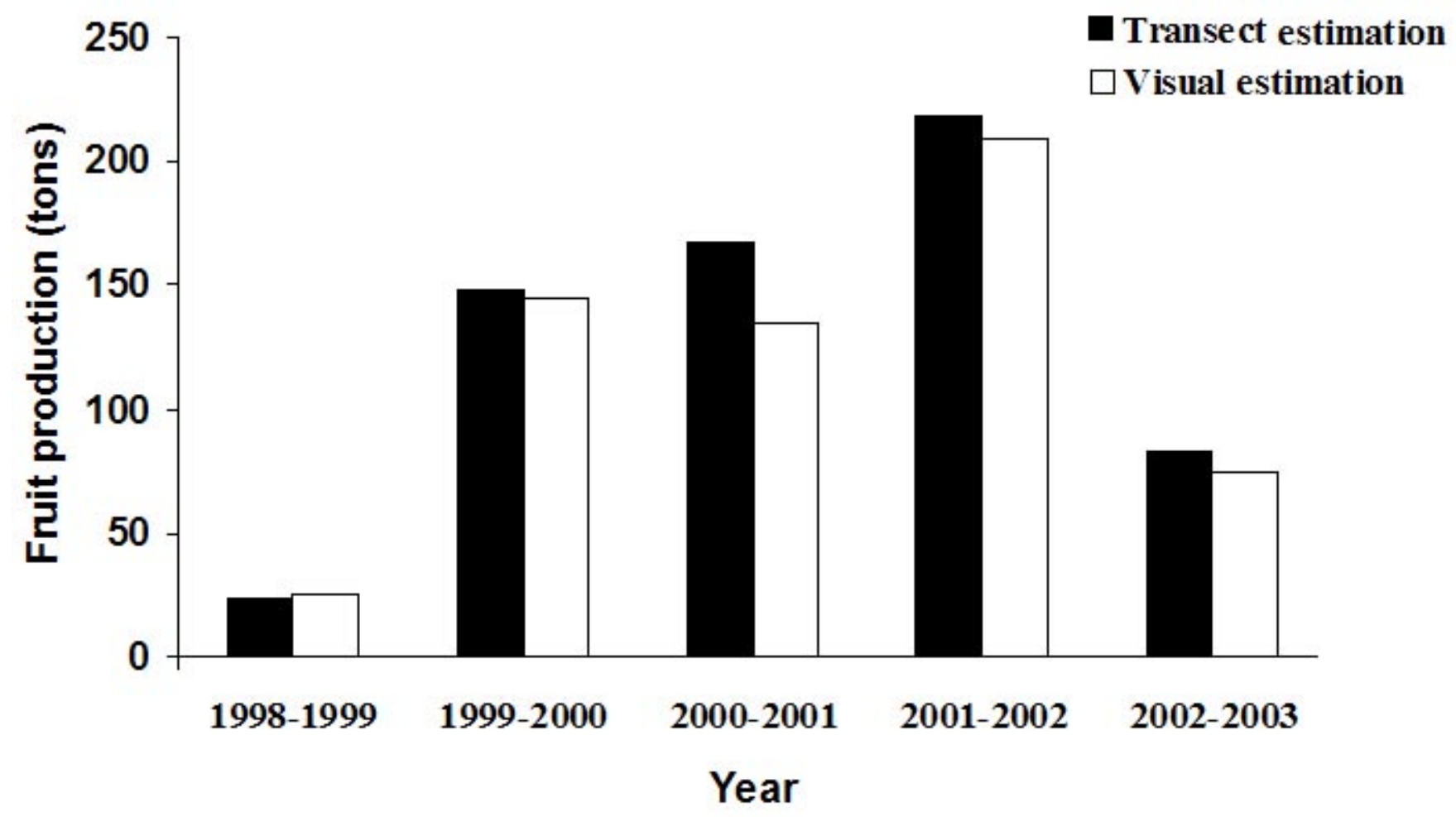

\section{Using participatory resource monitoring to assess harvest sustainability}

The PRM techniques used here provide insight on sustainability in several ways. First, they provide estimates of harvest rates, specifically the proportion of total fruits that were harvested each year. The rates of fruit harvesting documented here $(\sim 60 \%)$ appear to be sustainable, because simulations using matrix population models based on demographic data for both Phyllanthus emblica and $P$. indofishceri collected over an 8-yr period have shown that both species can withstand fruit harvesting at this level without succumbing to longterm population decline (T. Ticktin, R. Ganesan, and R. S. Setty, unpublished data). Many other tree species harvested for their fruits are also tolerant of high levels of fruit extraction (Ticktin 2004). However, sustainable harvesting is contingent on harvesting without branch cutting; when the latter occurs, even lower levels of harvesting can be unsustainable (Sinha and Bawa 2002, Sinha and Brault 2005). Similarly, frequent high-intensity fires decrease the quantity of amla fruits that can be harvested sustainably (Sinha and Brault 2005). Therefore, improving PRM protocols to reincorporate estimates of annual levels of branch cutting as well as to record the frequency of high-intensity fires could provide still better insights on sustainability.

Second, PRM provides insight on sustainability through the monitoring of regeneration. Here, the regeneration studies revealed high levels of seedlings and small saplings, suggesting continued germination and early growth of amla despite fruit harvesting. However, this monitoring does not provide evidence that populations are in fact growing, because there may be bottlenecks at other life stages. Our current research does now suggest important bottleneck stages for P. emblica. A key addition to PRM activities would be annual monitoring of individuals in the bottleneck stages 
Fig. 5. Differences in rates and types of harvest for amla (Phyllanthus emblica and P. indofishceri) in the Yelandur range, which has high rates of participatory resource monitoring (PRM) vs. the

Chamarajanagara range, where PRM rates are lower, of the Biligiri Rangaswamy Temple Wildlife Sanctuary in 1998.

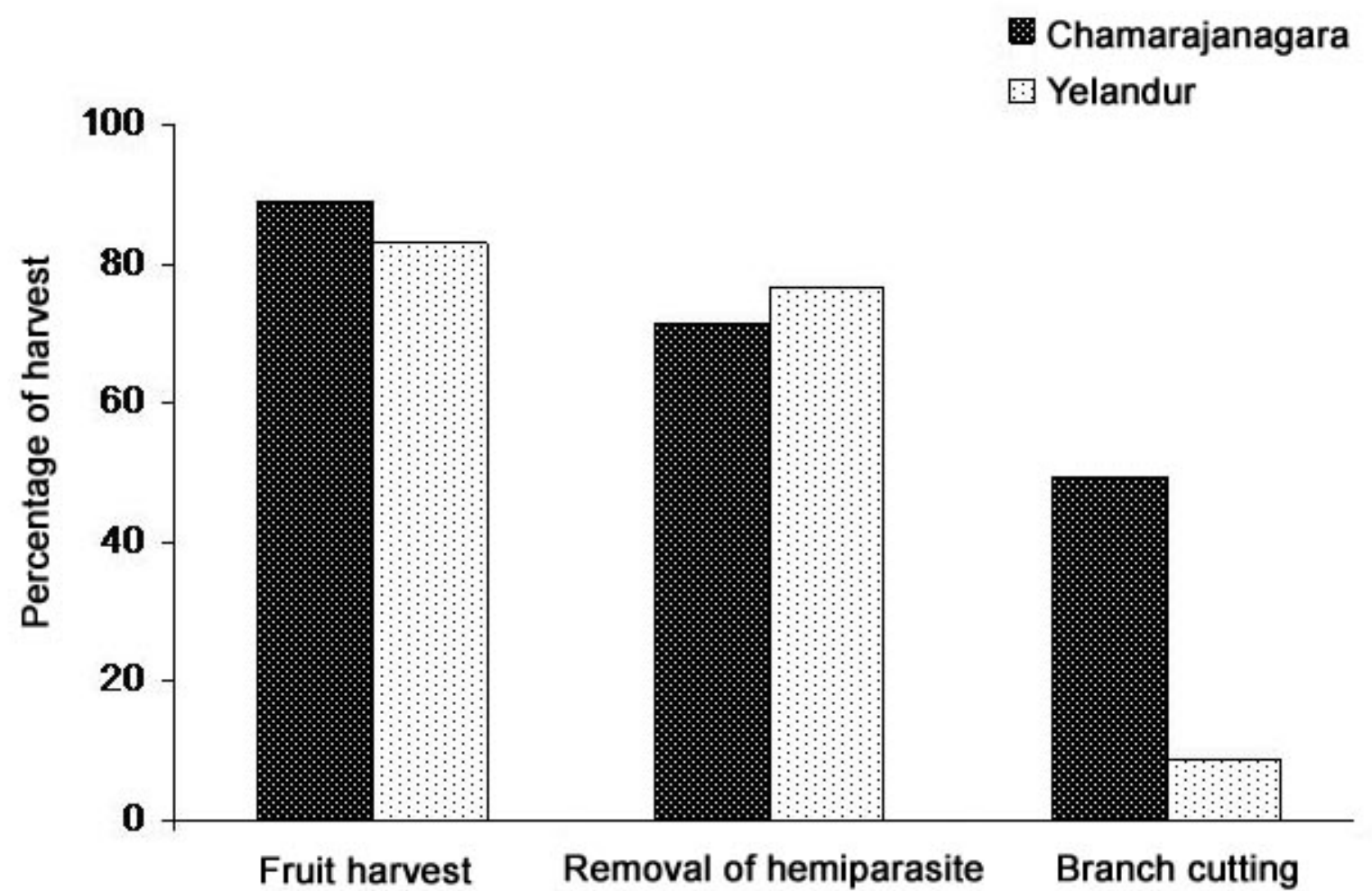

to assess trends and identify causes, which could then be discussed in the annual preharvest meeting.

In addition, PRM, and specifically the pre- and postharvest meetings, provides an outlet for the discussion of traditional ecological knowledge (TEK) that can ideally be used in adaptive management strategies and combined with scientific studies to develop further information on sustainability. However, in reality, the current tenurial regime restricts Soliga adaptive management strategies. For example, the Soliga maintain that low-intensity fires reduce hemiparasite infestation on amla trees. Scientific testing and community traditional knowledge illustrated that low-intensity ground fires kill almost $100 \%$ of hemiparasites and do not affect fruit production in $P$. indofischeri. Burning in dry deciduous forest, in contrast, tends to lead to canopy fires, which decrease $P$. emblica fruit productivity (Setty 2004). Although the Soliga have said that they would like to carry out lowintensity fires to control levels of both hemiparasites and alien invasive species in the understory, fire is prohibited in the BRT.

One limitation of our PRM activities is that they focused on monitoring amla populations but did not address potential impacts on other frugivores that also depend on the fruit. Although there is very little information in the literature on how wild fruit harvesting by humans can affect other organisms, Moegenburg and Levey (2002) showed that highintensity harvesting of the fruits of acai palms (Euterpe oleracea) in the Brazilian Amazon reduces avian frugivore diversity. However, they also found that low-intensity harvesting of fruit had no impact. 
Researchers from the Ashoka Trust for Research in Ecology and the Environment are currently involved in research in this area. In these ways, scientific research and PRM can work together, with the more time-intensive scientific studies helping to identify some of the key factors that may require monitoring.

\section{Challenges to "participation" in participatory monitoring and to institutionalization of monitoring}

Effective participatory monitoring systems involve the active participation and leadership of local harvesters in all stages and aspects of the monitoring program, including monitoring design, data collection and interpretation, and the formulation and implementation of adaptive responses. One of the biggest challenges in PRM is ensuring this nature and kind of participation. In our case, there were different levels of enthusiasm for and participation in different aspects of our participatory monitoring effort.

Participation appeared to be the highest in those aspects of monitoring that provided the most immediate benefits to harvesters. For example, estimates of annual fruit production rates are crucial for allowing harvesters to allocate time for harvesting and to anticipate the pay off from harvesting, and there was almost universal interest in this aspect of monitoring. In particular, almost $100 \%$ of participants welcomed the resource mapping exercise, which allowed for the identification of areas in which fruit production was high and enabled the processing unit to estimate the amount of fruit that would be available for marketing, which is important in obtaining a good trader to whom to sell their fruits. The success of the mapping exercise coincides with other research that has demonstrated that participatory mapping can be an effective tool in resource management (Lynam et al. 2007). Similarly, there are obvious direct benefits to harvesters who use better harvesting techniques, and there was good participation in reducing the cutting of main branches. These PRM activities also led to adaptive management, because harvesters reduced branch cutting and began to rotate harvest pressure when they felt that it was important to do so.

In contrast, changes in extraction rates can impact future productivity and harvest levels, but there was only limited interest by harvesters in estimating extraction rates. Similarly, monitoring regeneration is a time-consuming activity, the benefits of which are likely to be felt only in the distant future. There was no interest in monitoring regeneration without compensation for time and effort. Indeed, $75 \%$ of the Soliga harvesters showed little enthusiasm for participating in the monitoring of regeneration during our evaluation in 1999. Given the time involved in monitoring, they requested economic compensation for transportation and food from the enterprise component to assess regeneration. Their lack of interest may also have been simply because they were tired of so many PRM meetings and activities. Whatever the case, compensation was agreed to by the enterprise component. Specifically, a portion of the revenue gained by the Large-Scale Adivasi Multi-Purpose Societies (LAMPS) is set aside each year to pay for the regeneration monitoring, so that it is a permanent and long-term feature of the PRM.

In the case of the Soligas in the BRT, their lack of interest in estimating extraction rates and regeneration levels is probably a direct consequence of their uncertain tenure over their NTFP resources. Studies worldwide have illustrated that there is little impetus for harvesters anywhere to assess or reduce current harvest levels so as to ensure future yields, unless they have tenure over those resources and therefore know that their current sacrifices will result in future pay offs (Belcher and Schreckenberg 2007). In the BRT, the resources are owned by the state, which grants rights to collect NTFP. There are neither penalties for excessive harvesting nor incentives for judicious use of resources.

Once the participatory monitoring protocols described above were developed and modified, they were transferred to the LAMPS and enterprise units, which then started to cover the costs of monitoring by using a portion of the revenues from their NTFP sales. In theory, this kind of setup can be economically self-sufficient and therefore allow for long-term monitoring for sustainability. However, in reality, it is questionable what kind of monitoring these groups will be able to sustain, because only genuine user groups with tenure over resources can be in a position to provide incentives and make monitoring truly participatory. In addition, the full potential for adaptive management using PRM is limited, because some practices that the Soligas would like to reinstate to improve amla populations, such as controlled low-intensity fires, are prohibited by the Forest Department in the BRT. 
Complicating the situation further, in 2004 the Indian Forest Department banned NTFP collection for sale from the BRT and other sanctuaries and protected areas. Although the ban was not implemented for the first two years, it has been strictly enforced since April 2006. This has placed everything from harvesting and monitoring to processing and marketing on hold. It has also had implications for amla conservation. For example, since the ban, there have been instances of outsiders illegally cutting down amla trees for their fruits. Such practices, in contrast to the past, are no longer stopped by the Soligas because they have lost their rights to harvest.

However, the Indian government's Scheduled Tribes and Other Traditional Forest Dwellers Act, passed in December 2006, promises to change this situation. The act vests rights of ownership and access to collect, use, and dispose of minor forest produce that has been traditionally collected within or outside village boundaries to scheduled forestdwelling tribes. This includes the rights to locallevel processing, value addition, and marketing by the gatherers or their co-operatives or collective associations. The act vests individual and community forest rights and stipulates sustainable use, conservation duties, and co-management. Therefore, after implementation of this act, the Soligas should have the right to collect NTFP for both domestic consumption and sale and to manage their traditional forest areas. In this new context, the potential success for long-term participatory monitoring in the BRT and elsewhere in India greatly increases, as does its relevance. Soliga harvesters will be able to use PRM, including TEK and scientific information, to develop, test, and adapt strategies for sustainable NTFP use, including traditional strategies that may be sustainable but are currently not permitted in the BRT. This would provide them with the kinds of rights of access and use that would guarantee the security of the NTFP harvest for the community. The Soligas' cultural and spiritual connections to the forest and the strong sentiments expressed by many in the pre- and postharvest meetings concerning the need to conserve the forest for future generations underscore most of the Soligas' interest in sustainable forest use. This, combined with the overall level of interest in PRM and the fact that it is funded by LAMPS, suggests that, under the new act, there is good potential for the Soligas to continue and adapt the PRM activities over the longer term.

\section{CONCLUSION}

Our efforts over the past $10 \mathrm{yr}$ illustrate some participatory resource management (PRM) techniques that have proved to be highly effective and accurate, including strategies for participatory resource mapping, visual productivity estimation, and discussion and promotion of improved harvest techniques through postharvest meetings. These techniques provide insights into PRM strategies that can be adapted and tested elsewhere. Our finding that participatory visual estimates of fruit production taken while harvesters were in the forest for other activities can be accurate is particularly valuable given the time-intensive methods normally used to estimate nontimber forest products (NTFP) fruit production (Peters 2002). In addition, the preand postharvest meetings provided mechanisms for regulating harvesting levels by increasing awareness and discussion of current levels of fruit production, extraction, harvest patterns, and regeneration, and, given that harvesting rates and patterns were reported, they also generated peer pressure to harvest in a sustainable manner. In addition, the enterprise unit, community institutions, and Large-Scale Adivasi Multi-Purpose Societies (LAMPS) also stipulate conservation.

The establishment of the enterprise unit, which was created to promote value addition, and the direct linking of both the unit and LAMPS to PRM appears to have led to some economic benefits. The proportion of the rate received by amla harvesters in Yeladur each year fluctuates much less now and has been consistently higher than in other parts of the sanctuary (R. S. Setty, unpublished data). This is because of the purchase of amla by the local processing unit and the capacity building of Yelandur LAMPS directors, which has helped them to obtain better rates for their harvesters. In addition to increasing the Soliga's economic return from NTFP, the goal of the processing unit was to distribute additional profit to provide incentives to protect NTFP. Today, 869 harvesters are members of the processing unit, and over the past $10 \mathrm{yr}$ they have received a total of U.S. $\$ 11,310$ in the form of incentives. Apart from this, a part of the profits has also been used to support the education of Soliga children and local tribal institutions. The unit also employs 17 Soligas who receive about U.S. \$5454 per year in the form of salary.

Our work has also demonstrated the challenges involved in ensuring the interest of the local 
population in monitoring rates of extraction and regeneration, both of which are key elements in any monitoring program. However, at the same time it has demonstrated their potential; indeed, the quantitative data on rates of production, regeneration, and extraction that we have collected over the long term show that PRM holds great value for improving our understanding of the dynamics of NTFP harvest and its impacts. Despite the fact that many studies have illustrated that plant demographic rates (Menges 2000) and responses to harvest (Nantel et al. 1996) can vary greatly over time because of fluctuating environmental conditions, most studies that have assessed harvest sustainability for NTFP are based on two years of data or less (see Ticktin 2004). Short-term studies of the many NTFP that have variable demographic rates can miss critical information and result in misleading conclusions. Because long-term research on NTFP is not feasible in most cases, the potential for effective PRM methods to provide long-term ecological data is highly significant. The case of amla, in which LAMPS have undertaken both the responsibility and costs of monitoring, provides a model of how such a system could, under the right tenurial conditions, be supported and maintained over the long term. A priority for future PRM research, then, will be to work with harvesters to better develop appropriate and creative methods that ensure that harvesters have a long-term interest in obtaining this information and acting on it. Developing these techniques will only be possible when harvesters have tenure over their resources.

Responses to this article can be read online at:

http://www.ecologyandsociety.org/voll3/iss2/art19/responses/

\section{Acknowledgments:}

This work was supported by grants from the Biodiversity Conservation Network, the Ford Foundation, the Blue Moon Fund, and the Sir Dorabiji Tata Trust and by NSF grant OISE 0352827. We thank K. S. Murali, Sharachchandra Lele, and R. Ganesan for their useful suggestions in the field. We thank Ankila Hiremath and Nitin Rai for their inputs on the manuscripts. We thank the Soliga community for their participation and Soliga Abhirudhi Sangha for their encouragement. We thank Dr. H. Sudarshan, honorary secretary of Vivekananda Girijana Kalyana Kendra, and the
Karnataka Forest Department for their collaboration. Thanks to Jagdish Krishnaswamy and M. C. Kiran for providing Fig. 1.

\section{LITERATURE CITED}

Aravind, N. A., D. Rao, and P. S. Madhusudan. 2001. Additions to the birds of Biligiri Rangaswamy Temple Wildlife Sanctuary, Western Ghats, India. Zoos' Print 27(7): 541-547.

Bawa, K. S., G. Joseph, and S. Setty. 2007. Poverty, biodiversity and institutions in forestagriculture ecotones in the Western Ghats and Eastern Himalaya ranges of India. Agriculture, Ecosystems and Environment 121(2007):287-295.

Belcher, B., and K. Schreckenburg. 2007. Commercialization of non-timber forest products: a reality check. Development Policy Review 25 (3):355-377.

Cunningham, A. B. 2001. Applied ethnobotany: people, wild plant use, and conservation. Earthscan Publications, London, UK, and Sterling, Virginia, USA.

Ganesan, R., and R. S. Setty. 2004. Regeneration of amla, an important nontimber forest product from Southern India. Conservation and Society $\mathbf{2}$ (2):365-375.

Hegde, R., S. Suryaprakash, L. Achoth, and K. S. Bawa. 1996. Extraction of nontimber forest products in the forest of Biligirirangan Hills, India. 1. Contribution to rural income. Economic Botany 50:243-251.

Iqbal, M. 1993. International trade in non-wood forest products; an overview. FAO, Rome, Italy.

Kamathy, R. V., A. S. Rao, and R. S. Rao. 1967. A contribution to the flora of Biligirirangan Hills, Mysore State. Bulletin of the Botanical Survey of India 9:206-224.

Kusters, K., R. Achdiawan, B. Belcher, and M. Ruiz Pérez. 2006. Balancing development and conservation? An assessment of livelihood and environmental outcomes of nontimber forest product trade in Asia, Africa, and Latin America. 
Ecology and Society 11(2): 20. [online] URL: http: //www.ecologyandsociety.org/vol11/iss2/art20.

Lynam, T., W. De Jong, D. Sheil, T. Kusumanto, and K. Evans. 2007. A review of tools for incorporating community knowledge, preferences, and values into decision making in natural resources management. Ecology and Society 12(1): 5. [online] URL: http://www.ecologyandsociety.org/vol12/iss1/ art5/.

Menges, E. 2000. Population viability analyses in plants: challenges and opportunities. Trends in Ecology and Evolution 15:51-56.

Moegenburg, S. M., and D. J. Levey. 2002. Prospects for conserving biodiversity in Amazonian extractive reserves. Ecology Letters 5:320-324.

Murali, K. S., U. S. Uma Shanker, R. Uma Shaanker, K. N. Ganeshiah, and K. S. Bawa. 1996. Extraction of nontimber forest products in the forest of BiligiriRangan Hills, India. 2. Impact of NTFP extraction on regeneration, population structure, and species composition. Economic Botany 50:252-269.

Nantel, P., D. Gagnon, and A. Nault. 1996. Population viability analysis of American ginseng and wild leek harvested in stochastic environments. Conservation Biology 10:608-621.

Nepstad, D. C., and S. Schwartzman. 1992. nontimber products from tropical forests: evaluation of a conservation and development strategy. Advances in Economic Botany, Volume 9. New York Botanical Gardens Press, The Bronx, New York, USA.

Panayotou, T., and P. S. Ashton. 1992. Not by timber alone: economics and ecology for sustaining tropical forests. Island Press, Washington D.C., USA.

Peres, C. A., C. Baider, P. Zuidema, L. Wadt, K. Kainer, D. Gomes-Silva, R. Salomão, L. Simðes, E. Franciosi, F. Cornejo Valverde, R. Gribel, G. Shepard, M. Kanashiro, P. Coventry, D. Yu, R. Watkinson, and R. Freckleton. 2003. Demographic threats to the sustainability of Brazil nut exploitation. Science 302, 2112-2114.

Peters, C. M. 1996. Beyond nomenclature and use: a review of ecological methods for ethnobotanists.
Pages 241-276 in M. N. Alexiades, editor. Selected guidelines for ethnobotanical research: a field manual. New York Botanical Garden, The Bronx, New York, USA.

Ramesh, B. R. 1989. Evergreen forests of the Biligiri Rangan Hills, South India. Dissertation, French Institute, Pondicherry, India.

Salafsky, N., B. L. Dugelby, and J. W. Terbogh. 1993. Can extractive reserves save the rain forest? An ecological and socioeconomic comparison of nontimber forest product extraction systems in Peten, Guatemala, and west Kalimantan, Indonesia. Conservation Biology 7:39-52.

Setty, R. S. 2002. Sustainable harvest of nontimber forest products, Kannada manual. Ashoka Trust for Research in Ecology and the Environment, Bangalore, India.

Setty, R. S. 2004. Ecology and productivity studies on some nontimber forest products in Biligiri Rangaswamy Temple wildlife sanctuary. Dissertation. University of Mysore, Mysore, India.

Sinha. A., and K. S. Bawa. 2002. Harvesting techniques, hemiparasite and fruit production in two nontimber forest tree species in south India. Forest Ecology and Management 168:289-300.

Sinha, A., and S. Brault. 2005. Assessing sustainability of nontimber forest product extractions: how fire affects sustainability. Biodiversity and Conservation 14(14):3537 -3563.

Ticktin, T. 2004. The ecological consequences of harvesting nontimber forest products. Journal of Applied Ecology 41(4):11-21.

Ticktin, T., G. de la Pena, C. Illsley, S. Dalle, and T. Johns. 2002. Participatory ethnoecological research for conservation: lessons from case-studies in Mesoamerica. Pages 575-584 in J. R. Stepp, F. S. Wyndham, and R. Zarger, editors. Ethnobiology and biocultural diversity: proceedings of the Seventh International Society for Ethnobiology. University of Georgia Press. Athens, Georgia, USA.

Uma Shaanker, R., and K. N. Ganeshaiah. 1997. Mapping genetic diversity of Phyllanthus emblica: forest gene banks as a new approach for in situ conservation of genetic resources. Current Science 73(2):163-168. 
Uma Shaanker, R., K. N. Ganeshaiah, S. Krishnan, R. Ramya, C. Meera, N. A. Aravind, A. Kumar, D. Rao, G. Vanaraj, J. Ramachandra, R. Gauthier, J. Ghazoul, N. Poole, and B. V. Chinnappa Reddy. 2004. Livelihood gains and ecological costs of nontimber forest product dependence: assessing the roles of dependence, ecological knowledge and market structure in three contrasting human and ecological settings in south India. Environmental Conservation 31(3):242-253.

Walter, S. 2001. Non-wood forest products in Africa; a regional and national overview/Les produits forestiers non ligneux en Afrique; un aperçu régional et national. Working Paper/ Document de Travail FOPW/01/1. FAO, Forestry Department, Rome, Italy.

Vasquez, R., and A. H. Gentry. 1989. Use and misuse of forest-harvested fruits in the Iquitos area. Conservation Biology 3:350-361.

Vedeld, P., A. Angelsen, E. Sjaastad, and G. Kobugabe Berg. 2004. Counting on the environment: forest incomes and the rural poor. Environment Economics Series No. 98. World Bank, Washington D.C., USA. 